\title{
AVALIAÇÃO COMPARATIVA DA TOXIDADE DO ADESIVO DEENTINÁRIO ALL BOND 2 E DO CIMENTO DE ÓXIDO DE ZINCO E EUGENOL, QUANDO IMPLANTADOS NO TECIDO CONJUNTIVO SUBCUTÂNEO DE RATOS.
}

\author{
Carlos Alberto de Souza COSTA* \\ Josimeri HEBLING** \\ Heron Fernando de Sousa GONZAGA*** \\ Carlos BENATTINETO*** \\ Luis Carlos SPOLIDÓRIO*
}

\begin{abstract}
RESUMO
Com o objetivo de dar início ao estudo da biocompatibilidade do adesivo dentinário, All Bond 2 (Grupo experimental) quando comparado com o Óxido de Zinco e Eugenol (Grupo OZE - controle), estes materiais foram implantados no tecido conjuntivo dorsal de 20 ratos. Decorridos os períodos de 7, 15, 30 e 60 dias, biópsias foram realizadas, sendo que após processamento laboratorial de rotina, os cortes histológicos de 6 *m de espessura foram corados com H/E. Como resultado, aos 7 dias, o All Bond 2 promoveu intensa reação inflamatória com predomínio de células mononucleares, moderada necrose de contato e degradação de fibras colágenas, sendo que o cone capsular formado na área principal de análise foi amplo. Com o decorrer dos períodos, houve tendência à regressão do quadro inicial, mas a presença intensa de macrófagos e células gigantes ocorreu em alguns casos, até o último período de análise. No grupo controle, os achados histopatológicos foram menos intensos nos períodos iniciais de avaliação, sendo que aos 30 e 60 dias, o tecido junto à abertura tubular, área principal de análise havia passado pelo processo de reparação tecidual. Assim, apesar do adesivo dentinário All Bond 2 ter sido de maneira geral mais irritante do que o OZE, de acordo com as normas de ISO, foi possivel
\end{abstract}

\section{UNITERMOS \\ Adesivo dentinário; materiais biocompatíveis; óxido de zinco; eugenol.}

\section{SUMMARY}

A preliminary study of biocompatibility of dentin adhesive, All Bond 2 and Zinc oxide and Eugenol (ZOE) was realized after subcutaneous implantation in rats. The implants, poliethylene tubes filled with the dentin adhesives, were inserted into dorsal surgical pockets of 20 rats, and the animals sacrificed 7, 15, 30 and 60 days after. Serial sections of skin, stained with hematoxylin and eosin, showed in the first period ( 7 days) that All Bond 2 promoted a intense inflammatory reaction, moderate contact necrosis and collagen degradation. The ZOE promoted a slight reaction when compared with experimental group. During the experiment, the subcutaneous tissue presented tendency for healing, with organization of a fibrous capsule surronding the tubes. Althought for All Bond 2, into these fibrous tissue, was observed a mild mononuclear inflammatory cells. It was concluded that All Bond 2 is the aceitable materials when implanted in subcutaneous tissue of rats.

\section{KEY WORDS}

Dentin adhesives; biocompatible materials; Zinc oxide; eugenol.

\section{INTRODUÇÃO}

Para que as resinas restauradoras, especialmente as compostas, possam se aderir de forma mais eficaz e duradoura com a estrutura dental, e com isso, possibilitar longevidade às restaurações, éfundamental o emprego prévio de uma resina de baixa viscosidade (adesivo) que seja capaz de penetrar no íntimo da estrutura dental (esmalte e/ou dentina) e polimerizarse1.

Existem vários trabalhos22,24 que indicam que o emprego sistemático de uma resina fluida previamente à aplicação de resinas compostas, melhora consideravelmente o seu desempenho clínico, especialmente com relação à integridade marginal. Com raríssimas exceções, as resinas compostas são muito viscosas e portanto, apresentam limitada penetrabilidade. Porserem menos viscosos, os adesivos escoam melhor para dentro das microporosidades do esmalte e/ ou dentina, assegurando a formação de digitações mais longas na interface dente-restauração1.

A dentina apresenta uma estrutura basicamente tubular, constituída em peso por $70 \%$ de hidroxiapatita, $18 \%$ colágeno e $12 \%$ água 26 . Devido a essas características, o mecanismo de adesão à estrutura dentinária se torna mais complexo quando comparado ao esmalte, prova disto é o longo tempo já dedicado ao desenvolvimento dos adesivos dentinários 30 .

Os adesivos de 4a geração são, para fins de classificação, como aqueles que inicialmente removem a "smearlayer", descalcificam superficialmentea dentina inter e peritubular e expõem a rede de fibras colágenas para posterior im- pregnação desta área descalcificada por monômeros hidrofílicos; são chamados de "universais" devido a capacidade de união com diversos substratos.

Dentre os vários adesivos de $4 a$ geração presentes no mercado odontológico, o All Bond 2 (Bisco Dental Products, Itasca, IL) se destaca por suas excelentes propriedadesfísicas, quan-

Professor Assistente do Departamento de Patologia da Faculdade de Odontologia de Araraquara-UNESP.

** Professor Assistente do Departamento de Clínica Infantil da Faculdade de Odontologia de Araraquara-UNESP.

*** Professor Assistente Doutordo Departamento de Patologia da Faculdade de Odontologia de Araraquara-UNESP. 
do aplicados sobre o tecido dentinário, sendo ele composto por: um agente condicionador (ácido fosfórico à 10\%), primer (acetona, $2 \%$ de NTG - GMAe 16\% de bisfenil dimetacrilato - BPDM) e uma resina adesiva composta por Bis-GMA, HEMA e uretano dimetacrilato (UDMA).

Para se estabelecer uma forte união mecânica entre a resina e a estrutura dental, éfundamental que a maior área possivel de dentina entre em contato com o adesivo. Todavia, imprescindível a proteção adicional do complexo dentina/polpa com outro material em regiões profundas da cavidade, o que sem dúvida, limita a área dentinária disponívelà adesão1. Apenas em raríssimos casos (lesões de abrasão/erosão rasas) é possivel sua aplicação sem qualquer proteção prévia do complexo dentina/polpa13,14.

Muitos trabalhos de pesquisa têm mostrado que as substâncias comumente presentes nos sistemas adesivos tais como o Bis-GMA TEGDMA, HEMA, glutaraldeído e UDMA, apresentam efeito citotóxico definido $16,17,28$. To davia, a biocompatibilidade desses adesivos é muito discutida3,4,7,8,10,11,12, 15,25,29,31. O propósito desse trabalho foi estudar a compatibilidade biológica do adesivo dentinário All Bond 2 comparando-o com o cimento de óxido de zinco e eugenol (OZE), quando implantados no tecido conjuntivo subcutâneo de ratos, onde foi analisada a reação tecidual provocada por ambos materiais.

\section{MATERIALEMÉTODO}

Foram utilizados 20 ratos (Rattus Norvegicus, Holtzman) machos, pesando em média 280 gramas, os quais foram anestesiados porinalação de éter sulfúrico e posicionados em mesa operatória.

Após tricotomia na região dorsal, foi feita a antissepsia do campo operatório com tintura de iodo na proporção de 1:100. Na linha média, equidistante da inserção da cauda e da cabeça do animal, realizou-se uma incisão de aproximadamente $8 \mathrm{~mm}$ de comprimento como auxílio de uma tesoura de ponta romba e o tecido subcutâneo foi divulsionado lateralmente, formando duas lojas cirúrgicas, uma a cada lado da incisão, com aproximadamente $30 \mathrm{~mm}$ de profundidade.

Completadas as lojas cirúrgicas, iniciou-se o preparo dos adesivo dentinário All Bond 2 (Bisco) como indica o fabricante e do OZE ( $30 \mathrm{mg}$ óxido de zinco e $0,03 \mathrm{ml}$ de eugenol), sendo que os materiais em teste, foram introduzidos em tubos de polietileno de $10 \mathrm{~mm}$ de comprimento e $1 \mathrm{~mm}$ de diâmetro interno, os quais tinham uma das extremidades fechada à quente.

Para cada animal, o tubo, contendo o adesivo dentinário foi submetido a polimerização com luz visível durante 20 segundos, e então introduzido na loja cirúrgica do lado direito. $O$ tubo contendo o cimento OZE foi introduzido na loja cirúrgica do lado esquerdo, permanecendo ambos os tubos paralelos à incisão, a qual foi suturada.

Os ratos foram mantidos em gaiolas indivi- duais e alimentados com ração balanceada e água ad libitum. Decorridos 7,15, 30 e 60 dias após a cirurgia, 5 animais em cada período foram anestesiados por inalação de éter sulfúri$\mathrm{co}$, novamente tricotomizados e a área do implante foi removida, abrangendo suficiente tecido normal circunjacente.

Após processamento laboratorial de rotina, foram obtidos cortes histológicos seriados de 6 micrometros de espessura, os quais foram corados com hematoxilina e eosina.

O exame ao microscópio óptico procurouse comparar as reações teciduais provocadas por cada um dos materiais implantados junto à abertura tubular, sendo possivel assim prever, dentro das condições do experimento, a ação destes dois materiais em teste quando em contato com o tecido conjuntivo pulpar. Para isto, os seguintes eventos histológicos foram analisados: reação inflamatória, onde se determinou o padrão de células predominantes (células mononucleares ou polimorfonucleares); necrose; vasos sanguíneos; amplitude do cone capsular formado junto à abertura tubular, área principal de análise, onde se avaliou o padrão e característica desta estrutura (predomínio de fibras colágenas ou células); estes eventos histológicos foram graduados em: não significante, discreto, moderado e intenso. A aceitabilidade ou não do adesivo dentinário foi determinado através das indicações da ISO19, descritas no ano de 1984.

\section{RESULTADOS}

No primeiro período de avaliação, o All Bond 2 (Grupo experimental) promoveu intensa reação inflamatória, com predomínio de células mononucleares junto à abertura tubular, área principal de análise (Figura 1). Desta forma, o cone capsular era amplo, apresentando ainda numerosos vasos sanguíneos de pequeno calibre hiperemiados e moderada área de degrada. ção de colágeno e necrose de contato. Por outro lado, no grupo OZE (controle), o cone capsular formado junto à abertura do tubo era discreto, com quantidade intensa de células inflamatórias de predomínio mononuclear, localizadas em meio a vasos sanguíneos e moderada área de degradação de colágeno na região (Figura 5).

Com o decorrer do período, aos 15 dias, o tecido conjuntivo subcutâneo em contato como All Bond 2 manteve o mesmo padrão reacional porém menos intenso, daquele observado no período anterior, sendo histologicamente caracterizado como semelhante ao tecido de granulação (Figura 2). Para o OZE, ocorreu discreta regressão do quadro reacional, sendo que este se manteve menos intenso que o observado para o grupo experimental (Figura 6).

Aos 30 dias, para o grupo All Bond 2, não havia presença de área de necrose de contato, sendo que junto à abertura tubular, a reação inflamatória, agora discreta, era responsável pela formação de discreto cone capsular, onde era observado quantidade moderada de pequenos vasos sanguíneos, associados a numerosos fibroblastos e fibras colágenas entrelaçadas, caracterizando um tecido conjuntivo em processo de reparação. Em contato direto com o material em teste, havia tendência a organização de fibras colágenas e fibroblastos de modo a dar início a formação de um tecido fibroso denso, o qual mantinha continuidade com a cápsula fibrosa que envolvia lateralmente o tubo de polietileno (Figura 3)

Para o grupo controle, junto ao material implantado, havia a formação de uma cápsula fibrosa densa, a qual mantinha continuidade com àquela formada na superfície lateral do tubo. Adjacente, o tecido conjuntivo exibia numerosos fibroblastos e fibras colágenas entrelaçadas em meio a quantidade discreta de vasos sanguíneos de pequeno calibre, caracterizando um tecido conjuntivo que passou pelo processo de reparação tecidual.

Noúltimo período de observação, a cápsula fibrosa formada em contato com o All Bond 2 exibia a manutenção de quantidade discreta de células inflamatórias mononucleares de permeio. O tecido conjuntivo adjacente apresentava-se fibroso, com discretos capilares, não sendo detectadas células inflamatórias em quantidade suficiente para caracterizar um processo reacional (Figura 4).

Em apenas 6 casos ( 1 de 7 dias, 2 de 15 dias, 1 de 30 dias e 2 de 60 dias) houve exacerbação do quadro reacional, com presença intensa de macrófagos e células gigantes os quais nos dois últimos períodos de análise provocoua formação de verdadeiros nódulos reacionais em torno do material extravasado do tubo.

Para o grupo controle, o quadro histológico era semelhante àquele observado no período anterior (Figura 7)

\section{DISCUSSÃO}

A análise dos resultados do presente trabalho permitiu determinar que 0 adesivo dentinário All Bond 2 promoveu inicialmente, tensa reação inflamatória com predomínio de células mononucleares junto à abertura tubular, sendo observado ainda extensas áreas de degradação de colágeno e edema. Em contato comomaterial, havia moderada área de necrose. Esta alteração tecidual presente nos primeiros períodos de observação levou à formação de amplo cone capsular reacional na área principal de análise. Com o decorrer dos períodos, todos os eventos histológicos relatados regrediram, o mesmo ocorrendo com o cone capsular. No último período de observação, foi determinada a formação de uma cápsula fibrosa densa com discreta quantidade de células inflamatórias de permeio, sendo que este tecido mantinha continuidade com a cápsula fibrosa que envolvia as superfícies laterais e a extremidade fechada do tubo de polietileno. $\mathrm{Na}$ área anteriormente ocupada pelo cone capsular reacional, havia tecido em processo de reparação, onde se observou a presença intensa de fibroblastos e fibras colágenas entrelaçadas em meio a vasos sanguíneos de pequeno calibre.

No grupo controle, o cone capsular inicialmente discreto, composto porintensa quantidade de células inflamatórias mononucleares localizadas, vasos sanguíneos de pequeno calibree moderadaárea de degradação de colágeno 
e necrose de contato, regrediu com o decorrer dos períodos. Aos 30 e 60 dias de pós-operatório, uma cápsula fibrosa densa envolvia todo tubo de polietileno, sendo que o tecido conjuntivo adjacente estava reparado.

Os testes de implantação no tecido conjuntivo subcutâneo do rato foi indicado para avaliar a toxidade dos materiais odontológicos "in vivo"19. Os tubos de polietileno, usados na metodologia empregada no presente trabalho, são indicados por alguns pesquisadores27,32,33, os quais demonstraram a aceitabilidade deste material para a realização dos implantes subcutâneo em ratos.

Todavia, poucos trabalhos sobre a biocompatibilidade dos adesivos dentinários têm sido realizados quando comparamos com o número de trabalhos sobre as suas propriedades físicas, publicados na literatura9,21,30.

Como já relatado, o HEMA é uma substância encontrada na resina adesiva do All Bond2, estando presente também no primer de outros adesivos dentinários, como por exemplo Optibond(Sybron/Kerr).

No ano de 1992, Hanks et al.17 avaliou em cultura de células o efeito do HEMA sobre a sintese de DNA, de proteínas e respiração aeróbica destas células e concluiu que quando a substância em teste foi aplicada na concentração de 16 umol /litro, ela apresentou o efeito inibitório irreversivel sobre as células cultivadas. Em outro trabalho de pesquisa "in vitro" desenvolvido por Bouillaguet et al.2, foram cultivadas camadas de células Balb/c3T3 mouse fibroblasts (ATCCCCL 163, clone A31, American Type Culture Collection, Rockville, MD) sobre as quais foi aplicado o HEMA, e então determinada a ação citotóxica desta substância, cujo TC50 (concentração do material capaz de inibir $50 \%$ da atividade celular) diminuiu de $13 \mathrm{mmol} /$ I após $12 \mathrm{~h}$ de exposição para $4 \mathrm{mmol} / \mathrm{l}$ após 24 horas. Isto mostrou que quanto menor o TC50, maior a citotoxidade do material e que com o decorrer do tempo, o contato do HEMA com as células cultivadas levou a drástica redução do TC50, indicando que o contato prolongado do HEMA com as células, torna o material em teste cada vez mais citotóxico. Estes achados corroboraram ainda com aqueles de Hanks et al em 199217 e Bruce et al.5 em 1993.

No caso do Óxido de Zinco e Eugenol, Hensten-Petersen \& Helgeland 18 relataram que - OZE apresenta acentuado efeito tóxico quando aplicado sobre tecido mole ou em cultura de células. Lindquist \& Otteskog20 atribuíram esta citotoxidade do cimento de OZE ao eugenol livre. Estes achados foram corroborados por Costa et al. 6 ,os quais demonstraram que em cimentos de OZE onde a proporção de eugenol era alta, a reação inflamatória provocada por este material quando em contato com o tecido conjuntivo subcutâneo de rato era intensa, dificultando ainda o processo de reparação da área tecidual junto à abertura do tubo. Por outro lado, quando o cimento era preparado de tal forma a apresentar consistência viscosa $(0,7 \mathrm{mg}$ de óxido de zinco para $0,03 \mathrm{ml}$ de eugenol), 0 material apresentava pequeno efeito tóxico so- bre tecido conjuntivo.

Assim, no presente trabalho onde o OZE foi preparado com quantidade mínima de eugenol como indicado por Costa et al.5, este material apresentou baixo grau de irritação, enquanto que para o adesivo dentinário em estudo, foi possível observarintenso efeito citotóxico inicial do agente adesivo, onde foram detectadas extensas áreas de necrose de contato as quais pode-se sugerir, de acordo com os trabalhos anteriormente citados, ocorreram principalmente em função do Bis-GMA, UDMA e do HEMA presentes no adesivo dentinário All Bond 2. Hanks et al.16 em 1991, avaliaram várias substâncias presentes em adesivos dentinários e concluíram que em ordem decrescente de citotoxidade, o Bis-GMA foi maior que o UDMA o qual foi maior que o TEGDMA. Este achado pôde indicar que o adesivo dentinário em estudo pode ser, dentre vários outros no mercado, muito citotóxico, principalmente quando estes componentes estudados isoladamente sãomisturados. A resina adesiva do All Bond 2 possui, além do HEMA, o UDMA o qual foi avaliado por Nassiri et al.23 em 1994, utilizando 2 linhas de cultura de células humanas. Estes autores concluíram que o UDMA interfere com o ciclo celular, exibindo tanto efeito citostático quanto citotóxico.

De acordo com o presente trabalho, observamos em todos os períodos de análise que 0 All Bond 2 apresentou intenso potencial irritativo ao tecido conjuntivo subcutâneo do rato, havendo exacerbação do quadro reacional somente nos casos onde havia solubilização do material em teste para o interior do tecido conjuntivo, sendo que este acontecimento não foi observado para o grupo controle. Hanks, et al.16 mostraram ainda que a polimerização dos adesivos dentinários é prejudicada quando há presença de água, e como o HEMA é um componente do adesivo altamente solúvel em água e de baixo peso molecular, talvez isto explique porque no período de 15, 30 e 60 dias houveram casos de exacerbação da reação inflamatória em função destas propriedades do HEMA, presente no adesivo All Bond 2 .

Assim, muito se tem estudado sobre os sistemas adesivos e novos materiais estão sendo colocados no mercado odontológico, procurando suprir todas as deficiências existentes nos sistemas adesivos anteriores. Todavia todo material odontológico deve ter um equilíbrio entre suas propriedades físicas e biológicas. De acordo com os achados histológicos já citados, foi possivel observar que o adesivo dentinário estudado foi mais irritante ao tecido conjuntivo subcutâneo do rato quando comparado com OZE em todos os períodos de observação. Porém, a irritação decresceu com o decorrer do tempo. Isto fez com que o processo de reparação tecidual fosse mais lenta para o grupo experimental quando comparado com o grupo controle.

De acordo com os critérios indicados pelo ISO19 com relação a aceitação ou rejeição dos materiais em teste, foi possível concluir, dentro das condições experimentais, que o All Bond 2 apresentou biocompatibilidade aceitável como tecido conjuntivo subcutâneo do rato, exceto nos casos aonde o material sofreu maior solubilização, levando a intensas e extensas reações inflamatórias, as quais se prolongaram até o último período de análise.

Desta forma, o desenvolvimento do presente trabalho, deu início aos estudos da biocompatibilidade do adesivo dentinário AllBond 2, determinando a necessidade da realização de novas pesquisas "in vivo", com a finalidade de esclarecer a ação destes materiais quando em contato com tecidos pulpar e dentinário.

\section{AGRADECIMENTOS}

Aos Técnicos de Laboratórios José Antonio Sampaio Zuanon e Maria da Glória Vieira Cellie à SecretáriaHerminia Bassi Maio, pelo auxílio no preparo de lâminas e redação.

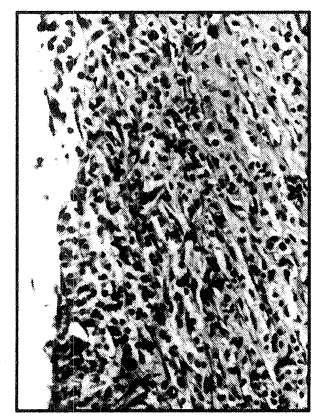

FIGURA 1 - All Bond 2 - 7 dias. Área junto à abertura do tubo, sendo observado intensa reação inflamatória dispersa, com predomínio de células mononucleares. $H / E ; 210 x$.

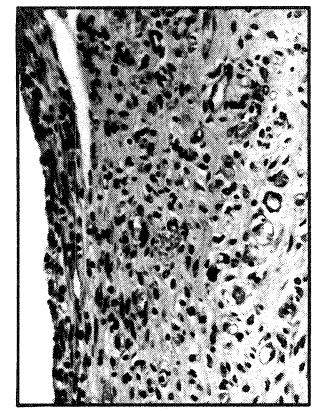

FIGURA 2 - All Bond 2 - 15 dias. Presença de tecido conjuntivo junto à abertura tubular semelhante ao de granulação. H/E.;250x.

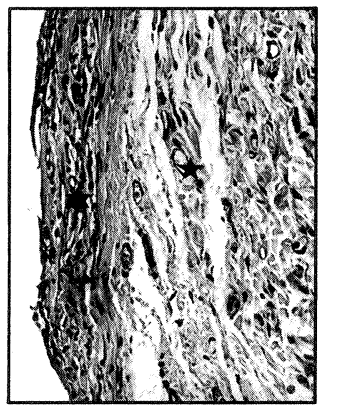

FIGURA 3 - All Bonf 2 - 30 dias. Tecido fibroso denso em contato como adesivo dentinário apresentando células inflamatórias mononucleares de permeio ( ). Oconjuntivo adjacente apresenta-se emprocesso final de reparação com moderada quantidade de vasos sanguineos de pequeno calibre ( ). H/E;210x.

R. Fac. Odontol. Porto Alegre v. 37 ก. 2 p. 3-6 Dez.1996 


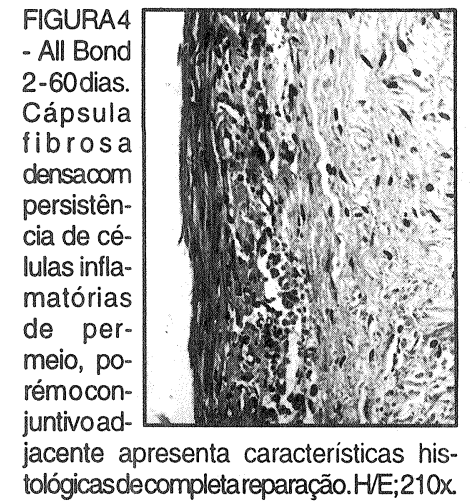

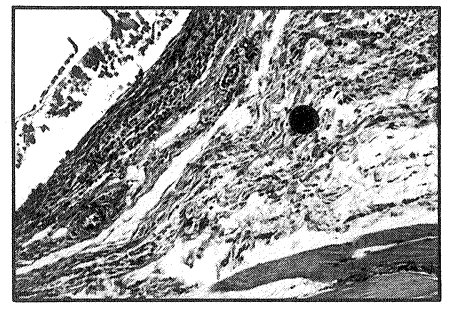

FIGURA 5-OZE - 7 dias. Intensa reação inflamatóriajunto ao materia implantado ( ), porém o conjuntivo subjacente exibe poucas células inflamatórias ( ). H/E; 120x.

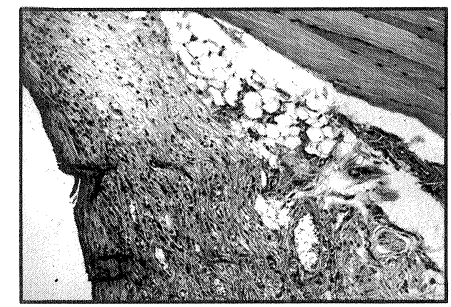

FIGURA 6 - OZE - 15 dias. Cápsula fibrosa densa em contato como OZE, sendo que o conjuntivo subjacente é caracterizado porpredomínio de fibras efibroblastos. H/E; 120x.

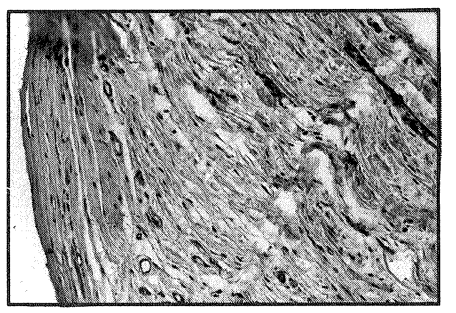

FIGURA 7-OZE - 60 dias. Cápsula fibrosa densa sem presença de células inflamatórias de permeio, sendo que o conjuntivo subjacenteapresenta característicashistológicas de normalidade. H/E; 160x.

\section{REFERÊNCIAS BIBLIOGRÁFICAS}

1. BARATIERI, L.N. et al. Dentística: procedimentos preventivos e restauradores. 5 . ed. Rio de Janeiro: Quintessence, 1991. p. 201-255.

2. BOUILLAGUET, S. et al. In vitro cytotoxicity and dentin permeability of HEMA (2 hydroxytil methacrylate).J. Endod., 1996 (prelo).

3. BROUILLET, J.L.; FRANQUIN J.C. Proprietes biologiques des resines composites, in matériel et méthodes en dentisterie restauratrice. Les composites postérieurs. Paris: Ed. SNPMD, 1987. p. 85-101.

4. BROUILLET, J.L. et al. Incidences biologiques d'un nouveladhesif dentinaire. Acta Odontostomatol . ,158: 291-318, 1987.

5. BRUCE, G.R. et al. Cytotoxicity of retrofill materials.J.Endod, 19:288-921993.

6. COSTA, C.A.S. et al. Compatibilidade Biológica do tecido conjuntivo subcutâneo de rato ao implante de óxido de zinco e eugenol (OZE), variando a proporção pó/ líquido e o tempo de envelhecimento do eugenol. Rev. Odontol. UNESP, 1996 (no prelo).

7. COX, C.F. et al. Histological response of infected cavities treated with Gluma and ScothBond dentin bonding agents. Am. J. Dent., 2: 194-198, 1989.

8. DOGON, L. Histology report on pulpal response to ScotchBond 2 adhesive system, report on file. St. Paul: 3M, 1987.

9. DUMSHA, T.C.;SYDISKIS, R.J. Cytotoxicity testing of a dentin bonding system. Oral Surg. Oral Med. Oral Pathol., 59: 637$641,1985$.

10. ELBAUM, R. et al. Estude in vivo de la biocompatibilité d'un adésif dentinaire a base de glutaraldehyde Hema. J.
Biomateriaux, 4: 47-51, 1989.

11. ELBAUM, R. etal. A histologic study of the biocompatibility of a dentinal bonding system. Quintessence Int. , 22: 901-910, 1991.

12. ERICK, J.D., WELCH, F.H. Dentin adhesives: do they protect the dentin from acid etching? Quintessence Int. , 7:533-54, 1986.

13. ESTHETIC composite bonding: techiniques and materials. Ontario: B.C. Decker Incorporated of Burlungton, 1987.

14. FINGER, W. Dentin bonding agents. Relevance of in vitro investigations. Am. J. Dent., 1 (sp.iss.): 184-188, 1988.

15. GERKE, D.C. Restoration of class III cavities using direct bonding resin systems. Aust. Dent. J. , 26: 89 - 91, 1981.

16. HANKS, C.T. et al. Cytotoxic effects of resin components on cultured mammalian fibroblasts. J. Dent. Res., 70: 1450-5, 1991.

17. HANKS, C.T. et al. Delineation of cytotoxic concentration of two dentin bonding agents in vitro. J. Endod., 18: 589-96, 1992.

18. HENSTEN-PETTERSEN, A.; HELGELAND, $K$. Evaluation of biologic effects of dental materials using four different cell culture techniques. Scand. J. Dent. Res., 85:291. $6,1977$.

19. INTERNATIONAL ORGANIZATION FOR STANDARDIZATION. Biological evaluation of dental materials. Genéve, 1984. 54p. (Technical Report 7405).

20. LINDQUIST, L.; OTTESKOG, P. Eugenol liberation from dental materials and effect on human diploid fibroblast cells. Scand. J. Dent. Res., 89: 552-6, 1981.

21. MERYON, S.D.; BROOK, A.M. In vitro cytotoxicity of three dentine bonding agents. J. Dent., 7:279-83, 1989.

22. MITCHEM, J.C. ; TURNER, L.R. The retentive strenght of acid etched retained resins - J. Amer. Dent. Assoc., 89:1107, 1974.
23. NASSIRI, M.R.et al. Aplication of low citometry to determine the cytotoxicity of urethane dimetacrylate in human cells. J. Biomed. Mat. Res., 28: 153-8, 1994.

24. NEWMAN, J.G.; EVASTE, M. The intermediate effect of low viscous fissure selants on the retention of resin restoratives in vitro. Proc. Finn. Dent. Soc., 71: 96, 1975.

25. NORDENVALL, K.I. et al. Pulp reactions and microorganisms under ASPA and Concise composite fillings. J. Dent. Child, 46: 449-53, 1979.

26. PERTINENT information on cosmetic, adhesive and restorative dentistry. Adept Report, 4: 33-45, 1990.

27. PHILLIPS, J.M. Rat connective tissue response to hollow polyethylene tube implants. J. Can. Dent. Assoc., 33:59-64, 1967.

28. RATHBUN, M.A. et al. Cytotoxicity of BisGMA dental composite before and after leaching in organic solvents. J. Biomed. Mat. Res., 25: 443-457, 1991.

29. SHERMAN, L.; GOLDEBERG, M. Choix de l'adhesif en fonction du degre de mineralisation d'une surface dentinaire. Chir. Dent. Fr. , 61,(551): 55-63, 1991.

30. STANFORD, J.W. Bonding of restorative materials to dentin. Int. Dent. J., 35: 1338, 1985.

31. TAGAMI, J. et al. Correlation among dentin depth, permeability and bond strength of adhesive resins. Dent Mater., 6: 45-50, 1990.

32. TORNECK, C.D. Reaction of ratconnective tissue to polyethylene tube implants. Part 1. Oral Surg. Oral Med. Oral Pathol., 21: 379-87, 1966.

33. TORNECK, C.D. Reaction of rat connective tissue to polyethylene tube implants. Part 2. Oral Surg. Oral Med. Oral Pathol., 24: 674-83, 1967. 